\title{
English regional dialect lexis in the names and occupations of the Gloucestershire Cotswolds: A reassessment of the relationship between names and dialects
}

\author{
David Harry Parkin
}

\begin{abstract}
A number of surname-based studies have presented a relationship between medieval regional dialect lexis and the distribution of associated modern-day surnames. However, by carrying out localised research, it appears that the two might not be so closely linked as previously thought, with discrepancies in the distribution of regionally specific names and equivalent occupational descriptions. As a result, there seems to be a need to reconsider the connection between regional lexicons and corresponding name stocks, which may have been less closely related, at a period of non-hereditary by-naming, than current knowledge suggests.
\end{abstract}

\section{Surnames and dialect}

It has been widely recognised that the regional distribution of certain by-names and surnames, ${ }^{1}$ from the medieval period up to the present day, can represent regional distinctions in Middle English (ME) dialect lexis and phonology. The history of English dialect phonology, and the evidence of surnames, has received much attention in previous research, with different studies investigating the phonology of the entire country (Kristensson 1967, 1987, 1995, 2001, 2002), of individual regions (e.g. Hjertstedt 1987), and of different forms of etymologically identical names, as well as certain morphological features (e.g. Barker et al. 2007; Viereck 2009). However, studies of variation in ME dialect lexis using name data are comparatively few. 
This is due to a relative lack of evidence, as the identification of different sets of names originating in synonymous English words is required, and such sets are sure to be less frequent than the sets of etymologically identical names of different form needed for phonological analysis. It seems that only Rogers (1995) and Barker et al. (2007) have discussed a number of sets of different synonymous names, with most research focusing on a single group, such as Fuller, Tucker and Walker (Schürer 2004: 55-56 and 68; Longley et al. 2007: 131-132). Due to the fairly limited amount of research on the name evidence of regional dialect lexis, the methodological issues and complications in such study have not been widely recognised. This paper will address some of these problems by focusing on the localised distribution of two sets of names with their origins in synonymous English words, namely Fuller, Tucker and Walker, and Weaver, Webb, Webber and Webster, in an attempt to further our knowledge of English surnames, regional dialect lexis, and the relationship between the two.

\section{Data}

This paper is borne out of research carried out as part of the author's doctoral study, which is a diachronic analysis of the names of the Cotswolds, from 1381 to c1600 (Parkin 2014). The data analysed are from the 1381 Gloucestershire poll tax (PT) returns and the 1608

Gloucestershire muster rolls (MR), and comparison of lexis in names and occupations will be employed to question the reliability of surname distribution as evidence of differences in regional lexicons. Note that the Gloucestershire PT returns are damaged, and do not cover the county in its entirety, but represent the Cotswold region well. This study is somewhat restricted by the coverage of extant records, as it cannot go beyond an analysis of the available data, and so the names studied in this paper, for all periods, are taken from the 
Cotswold settlements which appear in the Gloucestershire PT. From now on, any reference made to the PT or MR is specific to the records from the Cotswold region. Both the PT and MR have been transcribed, by Fenwick (1998) and Smith (1980) respectively, and the data analysed in this paper have been taken from these volumes.

1381 was a time when many names had only recently become hereditary, and some were still non-hereditary , as McKinley (1990: 32) states, "rather more than half the population had surnames by about 1350 " in the south of the country; the same pattern occurred roughly 100 years later in the north. Considering this, and the fact that "a universal stabilised orthography" (Scragg 1974: 64) only began to emerge after English became the language of official record in the 1430s, the names in the local records of the 1381 PT are likely to be a true representation of the local dialect of the time, assuming that a regional onomasticon can be equated with the relevant lexicon (and also assuming that non-standardised scribal practice would lead to the use of regionally specific lexical items, in addition to the phonologically representative spellings analysed in previous dialect studies). However, the names in the 1608 MR are at an altogether different stage of hereditary surname development. The extent to which the names of this time reflect the contemporary regional dialect lexis is unclear, though if similar to the phonological evidence then sixteenth and seventeenth century names might represent the dialect of an earlier period, much like how the family names of the present day “preserve fossilized forms of English" (Viereck 2006: 86).

Even though "the idea that there is, or should be, a standard or correct spoken form of English goes back at least to Puttenham" (Kerswill 2007: 47), a sixteenth century literary critic, "there is no evidence that any kind of non-regional pronunciation was in widespread use until the last quarter of the nineteenth century" (Kerswill 2007: 47). Clearly, then, there would have been considerable phonological dialect differences in spoken English in 1608, 
but whether or not these would have been apparent in written records of surnames from the time requires further consideration.

At a time when spelling was becoming standardised, it is possible that some surname variants would have been replaced by a more widespread form of the name, making it increasingly unlikely that surname forms were representative of regional dialect. However, as spelling was by no means completely standardised by 1608 , it is still possible that some names from this period represent elements of the contemporary regional dialect of the area in which they were recorded. Although, considering that most of these surnames would have first been formed as by-names about 200 years (at least) before 1608, some hereditary surname forms might instead represent the dialect at a time of non-heredity.

It seems that this is the case, with Viereck (2009: 77-79 and 95-97) showing that the modern distribution of the variants Pytt, Pett, Pitt and Putt (from Middle English pit "pit, hollow" (Old English pytt)), which reflect regionally specific ME phonological developments of the Old English (OE) vowel /y/, conforms to the expected pattern, hundreds of years after the names would have been formed. Using data in English phone books from 2004, Viereck shows that even today the distribution of the variants Pett, Petts and Putt roughly represent the particular regional developments of $\mathrm{OE} / \mathrm{y} /$ in ME, with Pett and Petts more common in the south-east of England, and Putt the usual form in the south-west.

The distribution of these modern surnames appears to be a fossilisation of ME dialect distribution. Of course, the spelt forms of such names must have been continually phonologically compatible with a contemporary local dialect of the region in which they were recorded, otherwise such spellings would be altered to fit in with what was regionally acceptable. However, this does not necessarily indicate that their forms were a result of a later contemporary dialect, so long as ME forms continued to represent acceptable 
phonology. Therefore, it must be considered that any dialectal features of name spelling at a time of heredity may not reflect the phonology of the time, but of a period of non-hereditary by-naming in the ME period. Similarly, in relation to this study of dialect lexis, the distribution of an hereditary surname which has its origin in a particular regional lexicon might represent the regional distribution of that lexical item at a time of non-hereditary by-naming, rather than the regional distribution of that item at the time when the hereditary surname in question was recorded. This has been suggested previously for the names Fuller, Tucker and Walker (see Schürer 2004: 56), which will now be discussed.

\section{Names and regional dialect lexis}

\subsection{The names Fuller, Tucker and Walker}

It is clear that Fuller, Tucker and Walker had, and still have, particular regional distributions (see Schürer 2004: 55-56 and 68; Longley et al. 2005: 131-132). As by-names, each of these "essentially refers to the same occupation" (Schürer 2002: 55), concerned with the treatment of wool cloth, as follows:

The process of fulling, that is to say, of beating or compressing the cloth in water, served first of all to shrink the cloth, reducing it in width by anything from a fifth to a half and in length to a corresponding extent ... Secondly, it served to 'felt' the cloth, so inextricably entangling the fibres that the pattern of the weaving often ceased to be visible ... In addition to shrinking and felting the cloth, making it close and firm, the fulling process also scoured it and cleaned it, with the aid of various detergents such as fuller's earth. (CarusWilson 1941: 40)

The apparently synonymous words, fuller, tucker and walker, for a person that fulled cloth as described above, had regionally specific usages in England. While it is probably only the 
word fuller which would be widely understood today, with "tucker, n.1" labelled as obsolete in the Oxford English Dictionary (OED) (online, 2000-) (and defined as "one whose occupation is the fulling and dressing of cloth; a fuller..."), and "waulker, n." labelled as historical (and defined as "a fuller of cloth"), all three still persist as surnames. Schürer (2004: 55-56 and 68) and Longley et al. (2005: 131-132) have shown that, in 1881 and 2003 respectively, Fuller was a name predominantly found in the south-east of England, Tucker in the south-west and Walker in the Midlands and the north. For clarity, distribution maps of these surnames from the 1881 census are presented in Figure 1, with darker areas signalling a greater concentration of the name in question.

$<$ FIGURE 1 about here>

From Figure 1, it is clear that Fuller was rare in the Cotswold region, the area from which the data studied in this paper came. The distributions of the names Tucker and Walker in the region are not so clear, though their proportional local poor law union distributions, given in Figure 2, show that Walker was the most common surname out of the three in 1881, perhaps reflecting the regional use of the word at a time close to hereditary surname establishment. ${ }^{2}$

\section{$<$ FIGURE 2 about here>}

Indeed, Schürer (2004: 56) found that "there is strong evidence to suggest that this broad regional distribution of the three surnames [in 1881] is similar to that of the early fourteenth century." It seems, then, that Walker was always the usual name out of three in the Cotswolds, presumably because it was the regional dialect term for anyone who fulled cloth. The idea that Walker was dominant in the region is supported by the names in the $1608 \mathrm{MR}$, where there were 19 bearers of the name Walker and no instances of Tucker or Fuller. These numbers are small, but, when compared with the 1881 distribution, it seems clear that the use 
of these three names in the Cotswolds followed the same pattern over a considerable number of generations. The slightly earlier Lay Subsidy Rolls of 1523-1527 (see Faraday 2009) further support the preference for the name Walker in the Cotswolds, with Tucker and Fuller being absent from records for the region.

Using data spanning about 358 years (from 1523 to 1881), it seems that Walker was consistently the usual surname out of the three, Fuller, Tucker and Walker. Considering this, it would be reasonable to assume that the word walker was used in the regional dialect of the Cotswolds, rather than fuller or tucker. However, the use of these words in the $1608 \mathrm{MR}$, outside of the recorded surnames, does not support this conclusion. As a description of a person's occupation, walker does not appear at all, while tucker is written 129 times, contradicting the surname evidence; fuller appears 14 times.

As the surnames might be a fossilisation of the usual regional word from a time when hereditary surnames were beginning to be established, it is possible that walker was the Cotswold dialect word in the $14^{\text {th }}$ century, but that the lexical isogloss shifted since this period and tucker became the more common dialect term. However, from an analysis of the 1381 PT, it does not appear that this was the case.

In a similar pattern to the 1608 data, the $1381 \mathrm{PT}$ shows that Walker was the common name out of the three, but tucker was the more common word for describing a person's occupation. As names, Walker appears 12 times, Tucker once and Fuller not at all. As occupational descriptions, walker is written once, tucker five times and Latin fullat' appears once. No meaningful conclusions could be drawn from these numbers alone, as the sample is too small to place any importance on the differences, but they do show the same usage as later records. This suggests that the use of tucker as a descriptive term in 1608 and the preponderance of Walker as a surname at the same time is not an indication of a change in regional dialect, as 
the difference in usage was long established; it was even apparent at a time when some names were descriptive of the bearer.

There must, therefore, be another explanation for the use of Walker and tucker in the Cotswolds. One possibility worth exploring is that scribal practice could have given the false impression of mixed usage of the two words in the region. McClure (1973: 193) states that "a variety of scribal influence may [...] come between the local speech forms and the written forms of the county rolls," and while this comment was made with respect to ME phonology, it is appropriate to dialect lexis too. If a scribe employed in the Cotswolds was originally from a further south-western part of England where tucker was part of the vernacular, his influence may cause this word to appear most commonly as an occupational description, while Walker would be most frequent as a name owing to it having been the usual Cotswold word. This explanation would be reasonable if the discrepancy in surname and lexical item occurred very rarely, but because it appears to be consistent over hundreds of years, occasional scribal influence is a very unlikely cause. It would suppose that all scribes of the records studied in this investigation were from the south-west of England, outside of the Cotswold region, which is not plausible.

Considering that tucker, out of the three words fuller, tucker and walker, was the most commonly used by Cotswold scribes outside of the name evidence, it is possible that it was the usual local dialect term. The frequency of the name Walker would then be unexpected, but could be due to migration from further north where walker was typically used. This, however, also seems unlikely, as the almost complete absence of the name Tucker in the Cotswolds, from 1381 up to 1608 , would mean that no hereditary surname was formed from the local dialect term tucker. 
Another possible explanation, it would seem, is that tucker and walker had developed subtly different senses in the county. While previous works have treated the names Fuller, Tucker and Walker as regionally specific terms for the same fulling process, some have not fully committed to the idea that they were synonymous. Schürer (2002: 55) states "each of these surnames essentially refers to the same occupation," with the slight level of uncertainty introduced by his use of the word "essentially" being of interest. Such caution may be deliberate as there were slightly different methods of fulling in the medieval period, which could have caused walking to be considered distinct from tucking and fulling.

Carus-Wilson (1941: 42) has found that "most probably hand fulling was reserved for small articles such as hats and caps, made usually of felt, while the long heavy broadcloths which came to form the staple of the English export industry were fulled by foot." It is not difficult to see how the action of fulling with the feet could become more readily associated with walking than the other two terms. Etymologically, the verb to walk is complex, with the $O E D$ (online, 2000-: "walk, v.") noting "it is remarkable that to the end of the Old English period the primary sense of the verb (strong and weak) is 'to roll', and that from the beginning of the Middle English period it is 'to move about, travel'."

It is surely the former sense that relates most closely to fulling cloth, with the $O E D$ (online, 2000-: "walk, v.") suggesting that the sense "to full (cloth) ... is presumably to be seen as a [specific] sense development of sense 2a," which is "to toss (something) about. Also: to work with the hand, roll up." However, considering the primary ME sense was 'to move about, travel', it is not implausible that the cloth-related sense of walk could have been linked specifically to fulling cloth with the feet, due to the walking (in the modern sense) action required to do so. 
If this was the case, the frequency of the surname Walker in the Cotswolds can be explained, even with competition from the word tucker in the near south-west. The large scale medieval wool trade of the Cotswolds makes it likely that fulling with the feet was a more common process than the hand fulling used for smaller items, causing walker to be the usual term in the region, and therefore Walker the usual name. However, the increased ambiguity of the verb to walk, due to its shift in sense from 'to roll' to 'to move about, travel', might have meant tucker became more appropriate and accurate as an official description of occupation with the related verb retaining its cloth-specific sense throughout the period studied (see $O E D$ online, 2000-: "tuck, v.1 - 3."), and was preferred to fuller for reasons of geography and dialect.

This suggestion cannot be proven, and is in no way meant to be conclusive, but along with the other possible explanations given it seems the most likely. The hypothesis that walker and tucker had developed slightly different senses in the Cotswolds appears to be supported by the fact that, within the $1381 \mathrm{PT}$, no person with the name Walker has the occupation tucker. At this time, when some names might still have been non-hereditary, it would be expected for Walker and tucker to have occurred alongside each other if they were considered to be equivalent in sense, just as fuller and tucker do in the case of Ricardo Toucar', fullat', from Througham in the hundred of Bisley, though this is assuming that the Latin fullat' represents the English fuller, which is not necessarily the case. The interpretation of Latin occupational descriptions and their translation is discussed further in Section 3.2. Walker and tucker also do not appear alongside each other in the $1608 \mathrm{MR}$, further supporting the notion that walker and tucker had developed different senses.

From this analysis of Walkers and tuckers in the Cotswolds, it is difficult to arrive confidently at any conclusions on their use in the region. While the national distribution in 1881 shows a 
regional concentration of the surname Walker, fitting in with the distribution of the surname in the $1608 \mathrm{MR}$ and the $1381 \mathrm{PT}$, the use of the occupational description tucker is puzzling. Considering that Walker was the usual name in the region out of the three arguably synonymous surnames Fuller, Tucker and Walker, it would be expected that this was due to walker being the usual word for a fuller in the Cotswolds, not tucker as it seems to have been. Perhaps, as suggested above, the importance of the wool trade to the region, known for producing the best wool "in England and therefore in Europe" (Trevelyan 1946: 87) in the fifteenth century, has caused Walker to be the common name and tucker a more accurate occupational description, but short of any medieval document stating exactly this point, this can only ever be hypothetical.

It is clear that the regional use of these words is not as simple as the national distribution of their corresponding surnames would suggest, emphasising the need for further research into the anthroponomastic evidence of dialect lexis at a local level. This is not just an issue for the names Fuller, Tucker and Walker in particular, but for all names with apparently regionally specific equivalents.

\subsection{The names Weaver, Webb, Webber and Webster}

It has been recognised in many previous works, both anthroponomastic and historical, that the profession of weaving has given rise to a number of different but apparently synonymous surnames. Aspin (1982: 4) mentions how "street and field names recall the old [wool] occupations, as do the surnames of many thousands of British people. Weaving has given us Weaver, Webster, Webber and Webb.” These four surnames had different national distributions, as described by McKinley (1990: 144), "Webb was found in the south of 
England, the south west, the south Midlands, and Essex with the adjoining part of Suffolk. Webster was originally the usual surname from the craft in the rest of East Anglia, the north of England, and Scotland. Webber and Weaver were both much rarer names, with only scattered examples of both". The exact period he is referring to here is not clear, but his description of the distribution of these names is very similar to Reaney's (1967: 356), who gives $13^{\text {th }}$ - and $14^{\text {th }}$-century sources.

Studies of more recent periods have found similar patterns. Rogers (1995: 52) notes that "Webb and Webster appear to divide the whole country between them, whereas the far less common Weaver and Webber have a more limited regional concentration." Barker et al. (2007: 257-264) also show this distribution, but none make comment on the significance of the distribution of the surname Webster, which requires further investigation. This agent noun suffix, -ster, "has been the subject of much debate among the experts, but the general conclusion has been that names such as Baxter, Brewster, Webster and so forth were originally the feminine forms of occupational terms" (McKinley, 1990: 140). Why a feminine form would persist as an hereditary surname in such great numbers and also have a clearly defined regional distribution is not clear. It is not plausible that weaving was mostly carried out by women in the north of England and men in the south, and so further work is required before names in -ster can be treated simply as regional variants of their masculine equivalents. Due to this uncertainty, the surname Webster has not been considered in this study, though the name does not occur in the 1608 Gloucestershire MR or the 1381 Gloucestershire PT, so this will not misrepresent the distribution and proportion of weaving names in the Cotswolds.

In the same way as for Fuller, Tucker and Walker, the distribution of these weaving surnames could also be considered as being indicative of regional language use in medieval England. It 
would therefore be expected for Webb and webbe to be the most common surname and occupational description, with small numbers of Weaver, Webber, weaver and webber; in 1881, Weaver was concentrated in the south-west, especially Devon, and Webber in the West Midlands. The evidence from the $1608 \mathrm{MR}$ is as expected, with 4 people named Weaver (0.067\% of total names), 43 named Webb $(0.72 \%)$ and no people named Webber. Webb is also the usual name in the 1381 PT, occurring 35 times $(0.69 \%)$, with no people named Weaver or Webber. However, much like the case of Walker and tucker, the usual occupational term is not webbe.

In the $1608 \mathrm{MR}$, out of the three options, only the word weaver is used as an occupational description. There are 433 people listed as weaver out of a total of 1,854 people with a specific occupation alongside their name, showing the importance of the cloth industry to the the Cotswolds at the time, but also that the usual local word for a weaver in 1608 was not the same as the usual surname. Unlike the case of Fuller, Tucker and Walker, however, the discrepancy in name distribution and occupational description seen in the $1608 \mathrm{MR}$ was not necessarily the same in the 1381 .

In the $1381 \mathrm{PT}$, while Webb occurs 35 times and Weaver and Webber not at all, webbe is not used as an occupational term; instead Latin textor is the word used to refer to a weaver, where it is English weaver in 1608. The use of Latin means it is not possible to ascertain whether webbe was the usual English word at the time, but the fact that it does not occur as an occupational description is not proof that it was not part of the spoken Cotswold vocabulary. For example, Smith is a frequent name in the 1381 PT, while the only equivalent occupational term used is Latin fabro' or faber, but no one could reasonably suggest that this means the word smith was not used at the time. In Oxfordshire, McKinley (1977: 149) noted that "the Latin words Textor, Testrix, Tixtor, and Telarius occur at times, mostly in the $12^{\text {th }}$ and $13^{\text {th }}$ 
centuries, as surnames or bye-names, with the literal meaning of 'weaver' [...] It is usually impossible to say what Middle English name is being translated by these terms, but in Oxfordshire they are probably being used to translate Webb." He bases this assumption on the frequency of the name $W e b b$ in the county, over the other synonymous but less frequent weaving names. Perhaps the same can be said of Latin textor, as an occupation, in the 1381 PT, making it most likely webbe was the usual word of the time. However, this cannot be certain, as it is equally plausible, on the basis of the discrepancy in name and occupation for Fuller, Tucker and Walker and their corresponding lexical items, that the usual word was not webbe, but was weaver, as it was in the $1608 \mathrm{MR}$.

The words webbe and weaver are the most likely options for the usual lexical item in the Cotswolds at the time of PT. It is clear that the word webbe was part of written English in 1381, with the $O E D$ (online, 2000-: “webbe, n.”) having examples of its use from the early $12^{\text {th }}$ to early $15^{\text {th }}$ century, when it must have been used for the surname Webb to have been formed. Similarly, there is evidence of weaver having been used around the time of the PT, with the first example in $O E D$ (online, 2000-: “weaver, n.”) being from 1362. The term webber is less likely to have been used, as its earliest use quoted in $O E D$ (online, 2000-: “webber, n.") is from about 1440.

If webbe was the usual term in the Cotswolds in 1381, as McKinley's (1977: 149) analysis of medieval by-names in Oxfordshire might lead us to believe, then it appears that the situation changed sometime before 1608. In $O E D$, there are no examples of webbe from later than the $15^{\text {th }}$ century, and there are also no examples of webber from later than 1518 , so it seems that weaver may have become the more common term, as it is in the $1608 \mathrm{MR}$. It is not possible to be certain whether webbe or weaver was the usual lexical item in the Cotswolds in 1381 from the available data, so it is difficult to arrive at any firm conclusions on the relationship 
between name and lexical item at this particular date, but the discrepancy between name and lexical item in the $1608 \mathrm{MR}$ is clear.

\section{Conclusion}

As found in the previous sections, the conflicting use of synonyms as names and occupations within the Cotswold region poses a problem to the study of local dialect using surnames. It is apparent that while Walker was the usual surname in the Cotswolds over a number of centuries, out of the three names Fuller, Tucker and Walker, it was not the usual word; tucker was most common as an occupational description. It also may have been that the regional dialect word for a weaver had changed sometime between 1381 and 1608, from webbe to weaver. Given that webbe and webber were obsolete in the $16^{\text {th }}$ century, according to quotations in the $O E D$, this would not have been specific to the Cotswolds, but the implications of this change are relevant to surname study in general.

This shows that the regional distributions of surnames at a single point in history are not always suitable as dialect evidence. There are localised complexities, like those identified in the Cotswolds, that cannot be explained with a map of national distribution at a given period, and which require further research before the relationship between name and local dialect can be fully understood. More generally, this initial investigation appears to show that a regional onomasticon cannot necessarily be directly linked to a corresponding regional lexicon, challenging current knowledge on by-name formation which suggests that naming "respects the 'national' or, rather, the linguistic and cultural divisions within the larger realm" (Clark 2002: 103). If this was the case, there would be a greater level of agreement between the regional distributions of name and occupational description in the Cotswolds, the absence of 
which raises the possibility that non-hereditary by-names were not quite so closely related to spoken vocabulary as current knowledge suggests.

Whether or not this extends beyond lexis to dialect phonology cannot be known without further investigation, but the findings presented in this paper suggest that such further investigation would be worthwhile. If discrepancies could be found between the distributions of phonological features in names and the distributions of phonological features in words used in non-onomastic texts, this would further support a distinction between regional naming practices and regional dialects. More generally, it would suggest that the names and phonology of onomastic data cannot be reliably equated with the lexis and phonology of spoken English from the same period, and this would mean that the use of onomastic data for historical dialectal analysis may not appropriate.

\section{References}

Archer, Steve. 2011. British $19^{\text {th }}$ Century Surname Atlas (Version 1.1). CD Rom: Archer Software.

Aspin, Chris. 1982. The Woollen Industry. Princes Risborough: Shire Publications.

Barker, Stephanie, Stefankai Spoerlein, Tobias Vetter and Wolfgang Viereck. 2007. An Atlas of English Surnames (University of Bamberg Studies in English Linguistics 52). Oxford: Peter Lang.

Carus-Wilson, Eleanora M. 1941. An Industrial Revolution of the Thirteenth Century. The Economic History Review a11 (1). 39-60.

Clark, Cecily. 2002. Socio-Economic Status and Individual Identity: Essential Factors in the Analysis of Middle English Personal-Naming. In David Postles (ed.), Naming, Society and Regional Identity, 101-121. Oxford: Leopard's Head Press.

Faraday, Michael A. (ed.). 2009. The Bristol and Gloucestershire Lay Subsidy of 1523-1527 (Gloucestershire Record Series 23). Bristol: The Bristol and Gloucestershire Archaeological Society. 
Fenwick, Carolyn C. (ed.). 1998. The Poll Taxes of 1377, 1379 and 1381. Part 1

Bedfordshire-Leicestershire. Oxford: Oxford University Press.

Hjertstedt, Ingrid. 1987. Middle English Nicknames in the Lay Subsidy Rolls for

Warwickshire. Uppsala: Acta Universitatis Upsaliensis, Studia Anglistica Upsaliensia 63.

Kerswill, Paul. 2007. Standard and Non-Standard English. In David Britain (ed.), Language in the British Isles, 34-51. Cambridge: Cambridge University Press.

Kristensson, Gillis. 1967. A Survey of Middle English Dialects 1290-1350: The Six Northern Counties and Lincolnshire. Lund: Gleerup.

Kristensson, Gillis. 1987. A Survey of Middle English Dialects 1290-1350: The West Midland Counties. Lund: Lund University Press.

Kristensson, Gillis. 1995. A Survey of Middle English Dialects 1290-1350: The East Midland Counties. Lund: Lund University Press.

Kristensson, Gillis. 2001. A Survey of Middle English Dialects 1290-1350: The Southern Counties, I. Vowels (except Diphthongs). Lund: Lund University Press.

Kristensson, Gillis. 2002. A Survey of Middle English Dialects 1290-1350: The Southern Counties, II. Diphthongs and Consonants. Lund: Lund University Press.

Longley, Paul A., Michael F. Goodchild, David J. Maguire and David W. Rhind. 2005. Geographic Information Systems and Science. Chichester: Wiley.

McClure, Peter. 1973. Lay Subsidy Rolls and Dialect Phonology. In Folke Sandgren (ed.), Otium et Negotium: Studies in Onomatology and Library Science Presented to Olof von Feilitzen, 188-194. Stockholm: Acta Bibliothecae Regiae Stockholmiensis 16 (Kungl. Boktr.).

McKinley, Richard A. 1977. The Surnames of Oxfordshire. London: Leopard's Head Press. McKinley, Richard A. 1990. A History of British Surnames. London: Longman.

OED online, see Simpson (2000-).

Parkin, David Harry. 2014. Change in the By-Names and Surnames of the Cotswolds. Unpublished $\mathrm{PhD}$ thesis: University of the West of England, Bristol.

Reaney, Percy H. 1967. The Origin of English Surnames. London: Routledge.

Rogers, Colin D. 1995. The Surname Detective: Investigating Surname Distribution in England, 1086-Present Day. Manchester: Manchester University Press.

Schürer, Kevin. 2002. Regional Identity and Populations in the Past. In David Postles (ed.), Naming, Society and Regional Identity, 202-227. Oxford: Leopard's Head Press.

Schürer, Kevin. 2004. Surnames and the Search for Regions. Local Population Studies 72. $50-76$. 
Scragg, Donald. G. 1974. A History of English Spelling. Manchester: Manchester University Press.

Simpson, John (ed.). 2000-. OED online (3rd edn of The Oxford English Dictionary).

Oxford: Oxford University Press. http://www.oed.com (accessed 1 November 2010 - 12 March 2013).

Smith, John. 1980 [1608]. Men and Armour for Gloucestershire in 1608. Gloucester: Alan Sutton.

Trevelyan, George M. 1946. English Social History. London: Longman.

Viereck, Wolfgang. 2006. Dialectology and Onomastics. Dialectologia et Geolinguistica 14. 86-103.

Viereck, Wolfgang. 2009. On the Geography of English Family Names. Dialectologia 3. 73 108.

\footnotetext{
${ }^{1}$ The term by-name is used to refer a non-hereditary name which was descriptive of the bearer, while surname is used to refer to an hereditary family name.

${ }^{2}$ Poor law unions were a kind of geographical unit in England, smaller than the county but usually larger than the parish.
} 